\author{
(1) Pelin A ğırgöl, \\ (1) Özlem Polat, \\ (1) İlkay Anaklı, \\ (D) Günseli Orhun, \\ (1) Arif Atahan Çağatay, \\ (1) Metin Kılıç, \\ (1) Perihan Ergin Özcan
}

\section{Yoğun Bakım Hastalarında Ventilator İlişkili Pnömoni Etkenlerini İole Etmede Minibal Tekniğinin Endotrakeal Aspirat ve Bronkoskopik Örneklerle Karşılaştırılması}

\author{
Comparison of Mini-bronchoalveolar Lavage Technique \\ with Endotracheal Aspirate and Bronchoscopic \\ Specimens in Isolating Ventilator-associated \\ Pneumonia Factors in Patients Under Intensive Care
}

Gelis Tarihi/Received : 10.06.2021

Kabul Tarihi/Accepted : 19.11.2021

\begin{abstract}
Pelin Ağırgöl, Özlem Polat, Ilkay Anaklı, Günseli Orhun, Perihan Ergin Özcan

Istanbul Üniversitesi Istanbul Tıp Fakültesi

Anesteziyoloji ve Reanimasyon Anabilim Dalı, Istanbul, Türkiye
\end{abstract}

\section{Arif Atahan Cağatay}

Istanbul Üniversitesi Istanbul Tıp Fakültesi, Enfeksiyon Hastalıkları ve Klinik Mikrobiyoloji Anabilim Dalı,

Istanbul, Türkiye

Metin Kllıc

Mers Ortak Sağlık Güvenlik Birimi, Manisa, Türkiye

Prof. Dr. Perihan Ergin Özcan (四,

Istanbul Üniversitesi Istanbul Tıp Fakültesi

Anesteziyoloji ve Reanimasyon Anabilim Dalı,

Istanbul, Türkiye

$\begin{array}{ll}\text { E-posta } & \text { : persude@gmail.com } \\ \text { Tel. } & : \text { :90 } 5336971009\end{array}$

ORCID ID : orcid.org/0000-0001-7986-4984
ÖZ Amaç: Çalışmamızda Yoğun Bakım Ünitesi (YBÜ)'nde nozokomiyal pnömoni tanısıyla izlenen hastalarda mini bronkoalveolar lavaj (mini-BAL) yöntemi ile klasik yöntemler olan endotrakeal aspirasyon (ETA) ve bronkoalveolar lavaj (BAL) yönteminin karşılaştııılması amaçlanmıştır.

Gereç ve Yöntem: Çalışmamız Istanbul Üniversitesi Istanbul Tıp Fakültesi Anesteziyoloji AD Yoğun Bakım Ünitesinde Şubat 2014-Ocak 2015 tarihleri arasında ventilator ilişkili pnömoni (VIP) şüphesiyle takip edilen 30 hastada gerçekleştirildi.

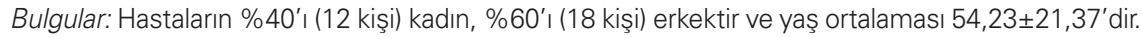
Ortalama mekanik ventilasyonda kalma süreleri ise $9,7 \pm 22,8$ gün olarak hesaplanmıştır. Hastaların ortalama SAPS III skoru 36,06 $\pm 8,46$, APACHE II skoru $21,36 \pm 4,90$ ve CIPS skoru ise $5,90 \pm 1,91$ olarak hesaplanmıştır

Sonuç: MiniBAL yönteminin bronkoskopi'ye göre tutarlıığı \%86,7, trakeal aspirata göre tutarlılığ \%63,3 olarak tespit edilmiştir. Endotrakeal aspirasyon ile bronkoskopi yönteminin birbiri ile tutarılığı \% 60 olarak hesaplanmıştır. Sonuç olarak YBÜ'de VIP şüphesi olan hastaların tanısında kullanılan yöntemlerin karşılaştırılmasında, miniBAL yönteminin erken ve güvenilir sonuçlar verdiği tespit edimiştir.

Anahtar Kelimeler: Ventilatör ilişkili pnömoni, mini-BAL, BAL, endotrakeal aspirat

ABSTRACT Objective: Our study aimed to compare the mini-bronchoalveolar lavage (mini-BAL) method with the classical methods of endotracheal aspiration (ETA) and BAL in patients followed up in the Intensive Care Unit (ICU) diagnosed with nosocomial pneumonia.

Materials and Methods: Our study comprised 30 patients who were followed up with a suspicion of ventilator-associated pneumonia (VAP) between February 2014 and January 2015 at Istanbul University, Istanbul Faculty of Medicine, Department of Anesthesiology, Intensive Care Unit.

Results: A total of $40 \%$ (12 people) of the patients were women, $60 \%$ (18 people) were men, and the mean age was $54.23 \pm 21.37$ years. The mean duration of mechanical ventilation was 9.7 \pm 22.8 days. The mean Simplified Acute Physiology Score (SAPS) III of the patients was 36.06 \pm 8.46 , the Acute Physiology and Chronic Health Enquiry (APACHE II) score was $21.36 \pm 4.90$, and the Clance Impostor Phenomenon Scale (CIPS) score was $5.90 \pm 1.91$. The consistency of the mini-BAL method, according to bronchoscopy, was $86.7 \%$, and its consistency, compared with tracheal aspiration, was $63.3 \%$. The consistency between the endotracheal aspiration and bronchoscopy method was $60 \%$.

Conclusion: Therefore, in the comparison of the methods used in the diagnosis of patients with suspected VAP in the ICU, mini-BAL gave reliable results in the early period.

Keywords: ventilator-associated pneumonia, mini-bronchoalveolar lavage, bronchoalveolar lavage, endotracheal aspiration 


\section{Giriş}

Hastane ile ilişkili enfeksiyonlar arasında üriner sistem enfeksiyonlarından sonra ikinci sırada olan nozokomiyal pnömoni, yatış sırasında inkübasyon döneminde olmadığı bilinen, yatıştan 48 saat sonrasında veya hastaneden taburcu olduktan sonraki ilk 48 saat içinde gelişen pnömoniler için kullanılan bir tanımlamadır (1). Bunun yanısıra ventilatör ilişkili pnömoni (VIP); entübasyon sırasında pnömonisi olmayan invazif mekanik ventilasyon desteği altındaki bireylerde, entübasyondan en erken 48 saat sonra gelişen nozokomiyal pnömonidir (1-3). Mekanik ventilatör bağımlı hastalarda pnömoni tanısı zordur, ve hala "altın standart" tanı yöntemi yoktur (4). Mekanik ventilatöre bağımlı, yoğun bakım hastalarında fiberoptik bronkoskopi tekniği ile yapılan örnekleme nozokomiyal pnömoni teşhisinde referans teknik olarak bilinmektedir. Ancak bu teknik invazif olup akut solunum yetmezliği olan hastalarda hipoksemi, tansiyon pnömotoraks ve bronşiyal hemorajiye yol açtığını bildiren literatürler de bulunmaktadır (5). Biz bu çalışmada, yoğun bakım ünitesinde (YBÜ) yatan 30 hastada, nozokomiyal pnömoni tanısında yeni bir yöntem olan mini bronkoalveolar lavaj (mini-BAL) yöntemi ile klasik yöntemler olan endotrakeal aspirasyon (ETA) ve bronkoalveolar lavaj (BAL) yöntemini karşılaştırmayı amaçladık.

\section{Gereç ve Yöntem}

Çalışmaya, Istanbul Üniversitesi İstanbul Tıp Fakültesi etik kurulundan 16/08/2013 tarihinde 14 sayılı toplantı ile 1136 numaralı etik kurul onayı alınmıştır. Çalışmamızda Şubat 2014Ocak 2015 tarihleri arasında Istanbul Üniversitesi Istanbul Tıp Fakültesi Anesteziyoloji AD Yoğun Bakım Ünitesinde VIP şüphesi olan 30 hastaya nozokomial pnömoni tanısında yeni bir yöntem olan mini bronkoalveolar lavaj (Şekil 1) yöntemi uygulanarak, klasik yöntemler olan endotrakeal aspirasyon ve BAL ile karşılaştırmak amaçlanmıştır.

Çalışmaya alınma kriterleri şu şekilde belirlenmiştir:

a) Hastalar 48 saatten daha uzun süre yoğun bakımda kalmış olmalı ve 24 saatten daha uzun süre endotrakeal yerleştirilmiş tüpü olmalıdır.

b) Bu hastalardan akciğer grafisinde yeni gelişen veya uzun süredir devam eden pulmoner infiltrasyonu olan ve aşağıdaki kriterlerden en az iki tanesini karşılaması gerekmektedir:
a. Ateş $\left(>38^{\circ} \mathrm{C}\right)$ veya hipotermi $\left(<36.5^{\circ} \mathrm{C}\right)$
b. Lökositoz (>10.10/L) veya lökopeni $\left(<4.10^{3} / L\right)$

c. Pürülan trakeal sekresyon

Ciddi hipoksemik hastalar $\left(\mathrm{PaO}_{2} / \mathrm{FiO}_{2}<120\right)$, hemodinamik açıdan stabil olmayan hastalar,

ciddi koagülasyon bozukluğu olan hastalar ve yoğun bakıma girişte akciğer enfeksiyonu olan hastalar çalışma dışında bırakılmıştır.

Çalışmaya alınan hastalardan ETA, mini-BAL ve BAL örnekleri aynı gün içinde 1 saat aralıklarla; önce ETA sonrasında sırasıyla mini- BAL ve BAL örnekleri alınmıştır. Örnekler enfeksiyon laboratuvarında gram boyama yapılmamış, direkt kültürlere ekilmiştir. ETA örneğinde $>100.000 \mathrm{cfu} / \mathrm{ml}$, BAL örneğinde > 10.000 cfu/ml koloni sayısı anlamlı üreme olarak kabul edilmiştir.

Hastalar; demografik özellikler (yaş, cinsiyet), entübasyon/ trakeotomi tarihi, mekanik ventilasyon süresi, önceki pulmoner enfeksiyonlar, örnekleme tarihi, örneklemeden önceki antibiyoterapi, giriş SAPS III skoru (Simplified Acute Physiology Score III), APACHE II (Acute Physiology and Chronic Health Evaluation) skoru, Klinik akciğer enfeksiyonu skoru (CPIS), minibal ve bronkoskopi antibiyogram sonuçları ve trakeal kültür sonuçları açısından değerlendirildi.

İstatistiksel analizler SPSS (Statistical Package for Social Sciences, version 15, Inc, USA) programı kullanılarak yapıldı. Sürekli değişkenler ortalama \pm standart sapma (SD) ve parantez içinde en düşük ile en yüksek değer olarak verildi. Kategorik değişkenler sıklık ve yüzdeler ile ifade edildi. Verilerin normal dağılıma uygunluğu Kolmogorov-Smirnov testi ile değerlendirildi. Gruplar arası farkı değerlendirmek için kategorik verilerde Pearson Ki- Kare ve Fisher'in kesin testi kullanıldı. Sayısal veriler için ise normal dağılıma uyan verilerde Student t testi ve Anova testi, Normal dağılım koşullarının sağlanmadığı durumlarda ise Mann-Whitney $U$ testi ve Kruskal Wallis Varyans analizi kullanıldı. Istatistiksel anlamlılık düzeyi olarak bütün testler için $p<0,05$ istatistiksel olarak anlamlı kabul edildi.

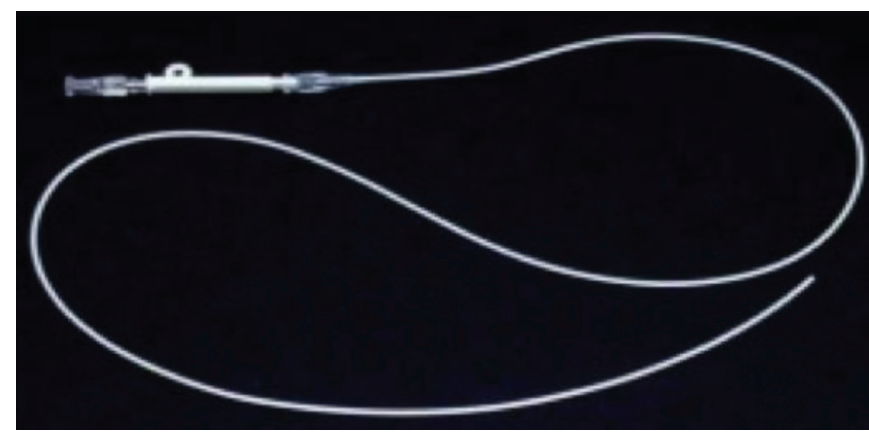

Şekil 1. Mini-BAL kateteri 


\section{Bulgular}

Çalışmaya dahil edilen 30 hastanın demografik verileri Tablo 1'de özetlenmiştir, \%40'ı (12 kişi) kadın, \%60'ı (18 kişi) erkektir. Hastaların yaş ortalaması $54,23 \pm 21,37$ yaş olup en küçük hasta yaşı 20 , en büyük hasta yaşı ise $87^{\prime}$ dir. Ortalama mekanik ventilasyonda kalma süreleri ise $9,7 \pm 22,8$ gün olarak hesaplanmıştır. Hastaların ortalama SAPS III skoru $36,06 \pm 8,46$, APACHE II skoru $21,36 \pm 4,90$ ve CPIS skoru ise $5,90 \pm 1,91$ olarak hesaplanmıştır.

Hastaların miniBAL yöntemi ile alınan örneklerindeki üreme durumu bronkoskopi ile karşılaştırıldığında; 26 hasta sonucunun tutarlı olduğu saptanmıştır. MiniBal yönteminin bronkoskopi'ye göre tutarlıı̆ı \% 86,7 olarak tespit edilmiştir (Tablo 2). Ayrıca hastaların miniBAL yöntemi ile alınan örneklerindeki üreme durumu trakeal aspirat ile karşılaştırıldığında; 19 hasta sonucunun tutarlı olduğu saptanmıştır. MiniBAL yönteminin trakeal aspirata göre tutarlıı̆ı \%63,3 olarak tespit edilmiştir. Endotrakeal aspirasyon ile bronkoskopi ile alınan örnekler karşılaştırıldığında; 18 hastada sonuçların tutarlı olduğu saptanmış olup 3 yöntemin birbiri ile tutarlıı̆̆ı \% 60 olarak hesaplanmıştır.

\section{Tartışma}

Yoğun bakım ünitesinde yatan hastalarda miniBAL tekniğinin bronkoskopi ile elde edilen sonuçlara göre duyarlıı̆̆ını incelediğimiz bu çalışmada, miniBAL tekniğinin $\% 86,7$ oranında bronkoskopik BAL sonuçları ile uyumlu olduğu gösterilmiştir.

Bronkoskopinin bulunmadığı merkezlerde VIP tanısının konmasında kullanılan en yaygın yöntem ETA kantitatif kültürü olmakla beraber, bu yöntemin en önemli dezavantajı üst solunum yolları florasına bağlı kontaminasyondur. Salata

\begin{tabular}{|l|l|l|}
\hline \multicolumn{2}{|l|}{ Tablo 1. Hastaların demografik verileri } \\
\hline \multirow{2}{*}{ Hasta } & Kadın & 12 \\
\cline { 2 - 3 } & Erkek & 18 \\
\hline Yaş & $54,23 \pm 21,37$ \\
\hline Mekanik ventilator süresi (gün) & $9,7 \pm 22,8$ \\
\hline SAPSIII skoru* & $36,06 \pm 8,46$ \\
\hline APACHE II skoru** & $21,36 \pm 4,90$ \\
\hline CPIS skoru*** & $5,90 \pm 1,91$ \\
\hline $\begin{array}{l}\text { *SAPS III skoru :Simplified Acute Physiology Score III,**APACHE II:Acute Physiology } \\
\text { and Chronic Health Evaluation skoru, *** CPIS skoru: Klinik akciğer enfeksiyonu } \\
\text { skoru }\end{array}$ \\
\hline
\end{tabular}

ve arkadaşlarının çalışmasında ETA kantitatif kültürünün özgüllüğü \%29-59 arasında bulunmuştur (6). Marquette ve arkadaşlarının (7) çalışmasında pnömoni tanısında, akciğer dokusunun histolojik incelenmesi altın standart olarak kabul edilmekle birlikte, ETA, PSB, BAL yöntemleri ile alınan örneklerin kantitatif kültürü birbirleri ile kıyaslamış ve yöntemler arasında benzer duyarlılık ve özgüllük saptanmıştır.

Mortalite açısından VIP'in erken zamanda tanısının konması, etken olan bakterinin doğru tanımlanması ve uygun tedavinin erken başlanması önemlidir. Christian ve arkadaşlarının (8) çalışmasında mini-BAL'ın direkt gram preparatının incelenmesi ve kantitatif kültürünün yapılması $\% 80$ hastada 2-24 saat içinde doğru tanı ve uygun tedavinin verilmesini sağlamıştır. Aynı çalışmada antibiyotik almayacak hastaların yaklaşık üçte ikisi belirlenmiş ve gereksiz antibiyotik kullanımı önlenmiştir.

Neves ve ark. (9) yaptığı çalışmada kritik hastalarda mini bal ve eta örnekleri ile pulmoner tüberküloz tanısının doğrulanması karşılaştııımıştır. Mini-BAL, ETA ile karşılaştırıldığında pulmoner tüberküloz tanısı için benzer sonuçlar verdiği görülmüştür. Ayrıca, Mini-BAL ile elde edilen solunum numunelerinde M.tuberculosis'in tespit edilebildiği ve pulmoner tüberküloz varsayımı olan kritik hastalarda ETA'ya kabul edilebilir bir alternatif olduğu gösterilmiştir. Ferreira-Coimbra ve ark. (10) VIP tanısında kullanılan tekniklerin de karşılaştıııdığı çalışmasında invaziv teknikler arasında mini-bronkoalveolar lavaj (miniBAL) ilk sırada, ardından bronkoalveolar lavaj, teleskopik kateter ve transbronşiyal biyopsi yer almakta idi. Bu teknikler arasında miniBAL en güvenli ve BAL daha riskli (transbronşiyal biyopsiden sonra, nadiren kullanılan) olarak saptanmıştır. Ayrıca mini-BAL uygulamasında daha az deneyime intiyaç olduğu belirtilmiştir. Bu durum, bazı yerlerde bronkoskopik BAL konusunda deneyimsiz ekibin olması veya deneyimli uygulayıcıların her zaman mevcut olmaması nedeniyle önemli olduğunu belirtmişlerdir.

Yapılan çalışmalarda, mini-BAL ve bronkoskopik fırça yöntemleriyle elde edilen örnek sonuçları arasında güçlü bir uyumun (\%77-88) varlığına dikkat çekilmektedir $(11,12,13)$. Buna karşın, Khilnani ve arkadaşları (12) distal hava yolu örneği elde etmek için kullanılan yöntemler içinde, doğru örneği elde etmede en başarısız yöntemin ETA olduğunu ifade etmişlerdir. Bacakoğlu ve arkadaşları (14) ETA ile miniBAL arasındaki uyumu \%67 olarak bildirmişler, Artuk ve arkadaşları (15) ise da ETA ile mini-BAL arasındaki uyum \%50 olarak düşük oranda tespit ettiklerini rapor etmişlerdir. 


\begin{tabular}{|c|c|c|c|c|c|c|c|c|c|c|c|c|c|c|c|c|c|c|c|c|c|c|c|c|c|c|c|c|c|c|c|}
\hline & & & onk & osko & pi ür & rem & eleri & & & & & & & & & & & & & & & & & & & & & & & & \\
\hline & $\begin{array}{l}\text { Hasta } \\
\text { no }\end{array}$ & 1 & 2 & 3 & 4 & 5 & 6 & 7 & 8 & 9 & 10 & 11 & 12 & 13 & 14 & 15 & 16 & 17 & 18 & 19 & 20 & 21 & 22 & 23 & 24 & 25 & 26 & 27 & 28 & 29 & 30 \\
\hline \multirow{30}{*}{ 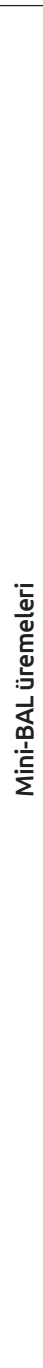 } & 1 & + & & & & & & & & & & & & & & & & & & & & & & & & & & & & & \\
\hline & 2 & & + & . & & & & & & & & & & & & & & & & & & & & & & & & & & & \\
\hline & 3 & & & + & . & & & & & & & & & & & & & & & & & & & & & & & & & & \\
\hline & 4 & & & & + & & & & & & & & & & & & & & & & & & & & & & & & & & \\
\hline & 5 & & & & & + & & & & & & & & & & & & & & & & & & & & & & & & & \\
\hline & 6 & & & & & & + & & & & & & & & & & & & & & & & & & & & & & & & \\
\hline & 7 & & & & & & & + & & & & & & & & & & & & & & & & & & & & & & & \\
\hline & 8 & & & & & & & & & & & & & & & & & & & & & & & & & & & & & & \\
\hline & 9 & & & & & & & & & + & & & & & & & & & & & & & & & & & & & & & \\
\hline & 10 & & & & & & & & & & + & & & & & & & & & & & & & & & & & & & & \\
\hline & 11 & & & & & & & & & & & + & & & & & & & & & & & & & & & & & & & \\
\hline & 12 & & & & & & & & & & & & + & & & & & & & & & & & & & & & & & & \\
\hline & 13 & & & & & & & & & & & & & + & & & & & & & & & & & & & & & & & \\
\hline & 14 & & & & & & & & & & & & & & + & & & & & & & & & & & & & & & & \\
\hline & 15 & & & & & & & & & & & & & & & & & & & & & & & & & & & & & & \\
\hline & 16 & & & & & & & & & & & & & & & & & & & & & & & & & & & & & & \\
\hline & 17 & & & & & & & & & & & & & & & & & + & & & & & & & & & & & & & \\
\hline & 18 & & & & & & & & & & & & & & & & & & + & & & & & & & & & & & & \\
\hline & 19 & & & & & & & & & & & & & & & & & & & + & & & & & & & & & & & \\
\hline & 20 & & & & & & & & & & & & & & & & & & & & + & & & & & & & & & & \\
\hline & 21 & & & & & & & & & & & & & & & & & & & & & + & & & & & & & & & \\
\hline & 22 & & & & & & & & & & & & & & & & & & & & & & + & & & & & & & & \\
\hline & 23 & & & & & & & & & & & & & & & & & & & & & & & + & & & & & & & \\
\hline & 24 & & & & & & & & & & & & & & & & & & & & & & & & + & & & & & & \\
\hline & 25 & & & & & & & & & & & & & & & & & & & & & & & & & + & & & & & \\
\hline & 26 & & & & & & & & & & & & & & & & & & & & & & & & & & & & & & \\
\hline & 27 & & & & & & & & & & & & & & & & & & & & & & & & & & & + & & & \\
\hline & 28 & & & & & & & & & & & & & & & & & & & & & & & & & & & & + & & \\
\hline & 29 & & & & & & & & & & & & & & & & & & & & & & & & & & & & & + & \\
\hline & 30 & & & & & & & & & & & & & & & & & & & & & & & & & & & & & & + \\
\hline
\end{tabular}

Bizim çalışmamızda ETA ile mini-BAL arasındaki uyum diğer çalışmalarla benzer şekilde \%60 olarak bulunmuştur.

Ileri yaş, nozokomiyal pnömoni riskini 2-3 kat artıran önemli risk faktörlerinden biridir. Bunun yanında mekanik ventilatöre bağlı her gün VIP gelişimi için \%1-3 oranında risk artışı taşımaktadır (16). Gedik ve arkadaşlarının (17) çalışmasında, VIP gelişen hastaların yaş ortalaması 56 yıl, ortalama mekanik ventilasyon süresi 20 gün olarak saptanmıştır. Khilnani ve arkadaşlarının (12) yaptığı çalışmada, yaş ortalaması 55.6 \pm 16.17 yıl, ortalama mekanik ventilasyon süresi $34.88 \pm$ 32 gün; Bacakoğlu ve arkadaşlarının (14) yaptığı diğer bir çalışmada ise yaş ortalaması $63.9 \pm 19 \mathrm{yıl}$, ortalama mekanik ventilasyon süresi $7.4 \pm 6.3$ gün olarak bildirilmişstir. Artuk ve arkadaşlarının (15) çalışmasında ise VIP hastalarının yaş ortalaması $68.23 \pm 16.19 \mathrm{yll}$, ortalama mekanik ventilasyon süresi ise $29.57 \pm 15.78$ gün olarak rapor edilmiştir. Ayrıca çok değişkenli lojistik regresyon analizi değerlendirilme sonucunda, mekanik ventilasyon uygulanan hastalarda hasta yaşı $(p<0.001)$ ve mekanik ventilasyon uygulama süresi ( $p<0.001)$, VIP gelişimi açısından birer risk faktörü olarak saptadıklarını ve yaş ile mekanik ventilasyon süresi arasında anlamlı bir korelasyon bulduklarını bildirmişlerdir. Bu çalışmada ise hastaların yaş ortalaması $54,23 \pm 21,37$ yaş olarak saptanmış olup ortalama mekanik ventilasyon süresi ise 9,7 $\pm 22,8$ gündür. Olguların ortalama değerleri genel olarak literatür ile uyumlu bulunmuştur. 
VIP tanısında kullanılan CPIS hesaplamasının en büyük dezavantajı, değişkenlerin subjektif yoruma açık olması ve bunun sonucunda skorlamanın yanlış hesaplanmasıdır (18). CPIS'ın 6'nın üzerinde bulunması pnömoni olasılı̆ı̆ıı güçlendirmektedir. Yapılan bir çalışmada VIP tanısı koymada; CPIS $\geq 6$ olarak hesaplanmasının duyarlıı̆ı \%93, özgüllüğü \%100 bulunmuştur. Ancak bazı araştırmacılar CPIS'ın, tedavinin değerlendirilmesi ve yönlendirilmesi aşamasında kullanılması gerektiğini belirtmektedirler. Khilnani ve arkadaşları (12), VIP tanısı alan hastaların ortalama CPIS skorunu $6.76 \pm 1.67$ puan; Bacakoğlu ve arkadaşları (14) ise $7.2 \pm 2.1$ puan olarak bildirmişlerdir. Artuk ve arkadaşları (15) ise VIP hastalarda CPIS skoru ortalaması $6.8 \pm 1.15$ puan olarak hesaplamışlardır . Bizim çalışmamızda ise CPIS skoru $5,90 \pm 1,91$ puan olarak hesaplanmıştır.

Sonuç olarak, YBÜ'de VIP şüphesi olan hastalarda nozokomial pnömoni tanısında kullanılan yöntemlerin karşılaştııılmasında miniBAL'ın erken dönemde elde edilen güvenilir sonuçları ve bronkoskopiye göre tutarlıı̆ının yüksek olması dikkat çekmektedir.

\section{Etik}

Etik Kurul Onayı: Çalışma için onay Istanbul Üniversitesi Istanbul Tıp Fakültesi Klinik Araştırmalar Etik Kurulu'ndan alınmıştır (karar no: 14, tarih: 16.08.2013).

Hakem Değerlendirmesi: Editörler kurulu ve editörler kurulu dışında olan kişiler tarafından değerlendirilmiştir.

\section{Yazarlık Katkıları}

Cerrahi ve Medikal Uygulama: P.A., Konsept: P.A., Ö.P., P.E.Ö., Dizayn: P.A., A.Ç., M.K., Veri Toplama veya Işleme: P.A., I.A., G.O., Analiz veya Yorumlama: A.Ç., P.E.Ö., M.K., Literatür Arama: P.A., Ö.P., Yazan: P.A., Ö.P., P.E.Ö.

Çıkar Çatışması: Yazarlar tarafından çıkar çatışması bildirilmemiştir.

Finansal Destek: Yazarlar tarafından finansal destek almadıkları bildirilmiştir. 


\section{Kaynaklar}

1. American Thoracic Society; Infectious Diseases Society of America. Guidelines for the management of adults with hospital-acquired, ventilator-associated, and healthcare-associated pneumonia. Am J Respir Crit Care Med. 2005 15;171:388-416.

2. Estes Rj, Meduri GU. The pathogenesis of ventilator-associated pneumonia: I. Mechanisms of bacterial transcolonization and airvvay inoculation. Intensive Care Med 1995; 21: 21-7.

3. Kollef $\mathrm{MH}$. What is ventilator-associated pneumonia and why is it important? Respir Care. 2005;50: 714-21.

4. Alp E, Voss A. Ventilator associated pneumonia and infection control. Ann Clin Microbiol Antimicrob. 2006;5:7. Published online Apr 6, 2006.

5. Koumbourlis A. Flexible fiber-optic bronchoscopy in the intensive care. Pulmonary and Seep Med 2010;38:5463.

6. Salata RA, Lederman MM, Shlaes DM, Jacobs MR, Eckstein E, Tweardy D, ve ark. Diagnosis Of Nosocomial Pneumonia In Intubated, Intensive Care Unit Patients. Am Rev Respir Dis. 1987;135: 426-462.

7. Marquette $\mathrm{CH}$, Georges $\mathrm{H}$, Wallet $\mathrm{F}_{\text {, }}$ Roman P, Sauhier F, Neviere R, Mathieu D, Rime A, Tonnel AB. Diagnostic Efficiency Of Endotracheal Aspirat With Quantitative Bacteial Cultures in Intubated Patients With Suspected Pneumonia. Am Rev Respir Dis 1993;148:138- 144.

8. Christian BB, Muriel F, Emmanuelle L, Stephanie H, Jean-Ralph Z, Chales C, 39 Bernard M. Contribution of Blinded, Protected Quantitative Specimens To The Diagnostic And Therapeutic Management of Ventilator Associated Pneumonia. 2005 Chest; 128:533-544.

9. Neves CP., Costa AG., Safe IP., et al. The role of mini- bronchoalveolar lavage fluid in the diagnosis of pulmonary tuberculosis in critically ill patients. BMC infectious Disease (2020) 20:229. https:// doi.org/10.1186/s12879-020-04954-3

10. Ferreira-Coimbra J., Ardanuy C., Diaz E., et al. Ventilator- associated pneumonia diagnosis: a prioritization exercise based on multi-criteria decision analysis. European Journal of Clinical Microbiology \& Infectious Diseases (2020) 39:281286 https://doi.org/10.1007/s10096-01903720-x

11. Kollef $\mathrm{MH}$, Silver $\mathrm{P}$, Murphy DM, Trovillion E. The Effect Of Late-Onset VentilatorAssociated Pneumonia In D etermining Patient Mortality. Chest. 1995; 108:1655- 1662.

12. Khilnani GC, Arafath TK, Hadda V, Kapil A, Sood S, Sharma SK. Comparison Of Bronchoscopic And Non-Bronchoscopic Techniques For Diagnosis Of Ventilator Associated Pneumonia. Indian J Crit Care Med 2011; 5(1): 16-23.

13. Tasbakan MS1, Gurgun A, Basoglu
OK, Ekren PK, Pullukcu H, Bacakoglu F. Comparison Of Bronchoalveolar Lavage And Mini-Bronchoalveolar Lavage In The Diagnosis Of Pneumonia In Immunocompromised Patients. Respiration 2011; 81(3): 229-35.

14. Bacakoğlu F, Uysal FE, Başoğlu ÖK ve ark. Ventilatör Ilişkili Pnömonide nonbronkoskopik mini-BAL'ın Tanısal Değeri. Solunum 2007; 9(3): 139-46.

15. Artuk C, Gül HC, Mert G, Karakaş A, Bedir O, Eyigün CP. Ventilatörle Ilişkili Pnömoni Tanısında Kullanılan Endotrakeal Aspirat Kültürü ile Mini-BAL Kültürünün Karşılaştırılması. Mikrobiyol Bul 2012; 46(3): 421-431.

16. Apostolopoulou E, Bakakos P, Katostaras T, Gregorakos L. Incidence And Risk Factors For Ventilator-Associated Pneumonia in 4 Multidisciplinary Intensive Care Units in Athens, Greece. Respir Care. 2003; 48(7): 681-8.

17. Gedik H, Yahyaoglu M, Fincanci M. The Diagnostic Accuracy Of Endotracheal Aspiration And Mini-Bronchoalveolar Lavage Cultures in The Diagnosis Of Ventilator-Associated Pneumonia. Nobel Med 2010; 6(2): 68- 74.

18. Pugin J, Auckenthaler R, Mili N, Janssens JP, Lew PD, Suter PM. Diagnosis Of Ventilator-Associated Pneumonia By Bacteriologic Analysis Of Bronchoscopic And Nonbronchoscopic "Blind" Bronchoalveolar Lavage Fluid. Am Rev Respir Dis 1991; 143(5): 1121-9. 